\title{
ARTIGOS
}

\section{A TRAJETÓRIA POLÍTICA DO SUJEITO HOMOSSEXUAL NA LUTA POR DIREITOS}

\author{
Alexandre Nabor França ${ }^{1}$ \\ Sergio Gomes da Silva
}

Resumo: Este trabalho tem por objetivo traçar o período histórico de luta pela emancipação da homossexualidade no Brasil pela mudança do status de "sujeito da sexualidade" para "sujeito de direitos". Isto será alcançado a partir da ressignificação da estruturação médico-científica da homossexualidade até início de algumas conquistas no plano dos direitos e do reconhecimento da cidadania de sujeito homossexual, passando pela inquisição moral cristã, criminalização, interdição militar até a constituição dos movimentos sociais LGBT.

Palavras-chaves: Sujeito Homossexual; Sujeito da Sexualidade; Sujeito de Direitos.

\begin{abstract}
"Nós não nascemos iguais: nós nos tornamos iguais como membros de uma coletividade em virtude de uma decisão conjunta que garante a todos direitos iguais. A igualdade não é um dado - ela não é physis, nem resulta de um absoluto transcendente externo à comunidade política".
\end{abstract}

(Hannah Arendt)

\section{Introdução}

O Brasil sempre foi palco de diversas expressões sexuais, desde a época em que foi colonizado por Portugal. Nesse clima de purgatório, da beleza e do caos, o Rio de Janeiro é uma cidade misturada por expressões camufladas que se intercalam sorrateiramente sem mostrar seu paradeiro, habitando proibições em torno das sexualidades consideradas anormais, desviantes e periféricas. Essa história marca um corpo que se faz presente em uma sociedade, que negocia significados simbólicos de luta por liberdade e igualdade.

\footnotetext{
${ }^{1}$ Psicólogo, Especialista e Mestre em Políticas Públicas em Direitos Humanos e Pesquisador do Laboratório de Pesquisas GE-SER NEPP-DH/UFRJ - alexnmfranca830@gmail.com

${ }^{2}$ Psicólogo, Pós-doutorando em Psicologia clínica pela USP e Psicanalista; Pesquisador do Laboratório de Pesquisas GE-SER NEPP-DH/UFRJ - sergiogsilva1 @ gmail.com Vol. 01, N. 04, Out. - Dez., 2018 -www.revistas.unilab.edu.br/index.php/rebeh
} 
Este artigo busca resgatar a historicidade da trajetória do homem homossexual brasileiro, da cidade do Rio de Janeiro, na luta por direitos e por reconhecimento social como sujeito de direitos. Nessa trajetória perpassa a linha do tempo a passagem histórica de luta pelo reconhecimento de si na constituição de um movimento político e social identitário. Serão resgatados, no texto, alguns pontos históricos importantes sobre as violências contra as homossexualidades ocorridas no mundo para respaldar o início da luta do movimento homossexual no Brasil.

Deste modo, questiona-se: a homossexualidade como prática sexual e o

homossexual como sujeito, na contemporaneidade, de maior aceitação e reconhecimento no espaço social? Este reconhecimento está associado às lutas dos movimentos sociais LGBT? Considera-se que a luta de emancipação homossexual no âmbito do reconhecimento de direitos do sujeito da sexualidade possibilitou, mais adiante, o surgimento do movimento LGBT na luta por "sujeitos de direito".

As lutas por liberdade sexual vão se configurando nas relações de poder, moldando as configurações históricas, sociais, territoriais e culturais, ou seja, novas formas de subjetividades. As homossexualidades, vividas como expressão do desvio de acordo com a heteronormatividade, acirravam as lutas por liberdade sexual e pela aceitação de suas subjetividades. Essas subjetividades se articularam com a concepção da politização da homossexualidade como mobilização coletiva na construção de diretrizes, leis e políticas públicas que viabilizasse o reconhecimento existencial das orientações sexuais nãoheterossexuais no Rio de Janeiro. Esses desdobramentos sociais se configuraram pela visibilidade de uma possível diversidade sexual encontrada, primeiramente, nas Paradas do Orgulho Gay e, mais adiante, nas Paradas LGBT, compondo características idiossincráticas importantes de representatividade no arco-íris na bandeira, nos letramentos linguísticos e comportamentais, nas roupas e nos corpos moldados pela cultura hedonista.

Neste trabalho, resgatamos historicamente a trajetória do homem homossexual na luta pelo seu reconhecimento e transição da imposição de "sujeito da sexualidade" para o estatuto de "sujeito de direitos", passando pela inquisição moral cristã, interdição militar, surgimento da AIDS e a constituição do movimento social. Defenderei a hipótese de que a homossexualidade passou por um processo sociocultural de aceitação na sociedade, através de sua incursão política na construção do status de sujeito de direitos.

Vol. 01, N. 04, Out. - Dez., 2018 -www.revistas.unilab.edu.br/index.php/rebeh 


\section{O sujeito da sexualidade na moral médico-científica}

A constituição de um "sujeito da sexualidade" não é nova. Ela dista há aproximadamente dois séculos, a partir do momento em que se inaugura um conhecimento acerca da sexualidade daquilo que é normal e patológico entre homens e mulheres na era moderna, ou seja, da compreensão de uma essência identitária, fazendo com que o binômio sexo-gênero fosse responsável pela desqualificação moral de determinadas sexualidades periféricas a partir de sua inscrição na sociedade.

Conforme mostrou Michel Foucault, o "sujeito da sexualidade" foi constituído a partir do "uso dos prazeres", da "hipótese repressiva", do "dispositivo da sexualidade" e de uma "microfísica e micropolítica do desejo", objetivando analisar as práticas pelas quais os indivíduos foram levados a prestar atenção a eles próprios, a se decifrarem, se reconhecerem e se confessarem como sujeitos de desejo, estabelecendo de si para consigo uma relação que lhes permitia descobrir, no desejo, a verdade de seu ser, do seu sexo, seja ele natural ou decaído (FOUCAULT, 1988).

Para Foucault (1988, p. 47) os "comportamentos polimorfos [formas sexuais] foram, realmente, extraídos do corpo dos homens, dos seus prazeres; ou melhor, foram consolidados, instalados, isolados, intensificados, incorporados". E os meios pelos quais se extraiam os saberes destes corpos eram através dos exames médicos, formulados pelo gozo de um novo modelo científico por meio da produção da classificação das patologias

e taxionomia. Agora não era mais os confessionários religiosos, mas outro tipo de confissão que se fazia como meio de intervenção que detinham o controle dos corpos por meio do discurso médico-científico. A medicina psiquiátrica, como um saber científico detinha um saber e o poder de intervenção sobre os sujeitos. Neste sentido "a causalidade no sujeito, o inconsciente do sujeito, a verdade do sujeito no outro que sabe, o saber, nele, daquilo que ele próprio ignora, tudo isso foi possível desenrolar-se no discurso do sexo" (FOUCAULT, 1988, p. 69).

O discurso do sujeito da sexualidade será categorizado e interditado pela scientia sexualis constituindo uma economia política baseada na vontade de saber. Tudo ou qualquer possibilidade que estivesse fora dos modelos sexuais seria interditado por este poder constituído pelo saber das ciência sexuais. O "poder tentacular" estava em todas as partes, porém não era situado fisicamente, pois ele "não é uma instituição e nem uma Vol. 01, N. 04, Out. - Dez., 2018 - www.revistas.unilab.edu.br/index.php/rebeh 
estrutura, não é uma certa potência de que alguns sejam dotados: é o nome dado a uma situação estratégica complexa numa sociedade determinada" (FOUCAULT, 1988, p. 89), ou seja, o poder é uma articulação constituída por um saber hegemônico que institui dizer ao outro o que ele é e o que deve ser na sociedade. É a constituição do sujeito sexual que instituiu a configuração do que deve ser um sujeito homem ou mulher na sociedade.

Este pensamento forjou um sistema heteronormativo como dispositivo social de produção de feminilidade e masculinidade que se identificam como centros naturais e anatômicos da diferença sexual e de gênero (PRECIADO, 2014). Assim, a heterossexualidade tornou-se uma tecnologia social que fundou a arquitetura do corpo como uma política de naturalização para os comportamentos sexuais e de gênero. Por outro lado, a homossexualidade se constituirá em um acidente, sendo então estigmatizada como prática antinatural e anormal em benefício da estabilidade do sistema heteronormativo.

Para a cultura ocidental patriarcal burguesa, a constituição da família nuclear foi o primeiro simulacro institucional criado para tentar erigir uma possível naturalização das relações entre homens e mulheres, pautado na ficção de que a mulher nasceria única e exclusivamente para o homem, segundo a metafísica dos corpos (LAQUEUR, 2001; COSTA, 1995).

O ideal de família burguesa foi constituído entre os séculos XV e XVII e não tinha como realidade os sentimentos e valores do casal romântico. O casamento proporcionava segurança e permanência dos bens adquiridos por herança ou patrimônio, forjando a ideia de família e propriedade privada (ENGELS, 1978). Foi somente a partir do século XVIII, que a configuração da família burguesa começou a se constituir como instância de família nuclear calcadas nos sentimentos. A ideologia moral cristã favorecia a procriação e a propagação da espécie a partir da união entre um homem e uma mulher. Todo o amor fora do casamento é condenado, conforme a doutrina de São Paulo. Tratava-se de apagar o desejo, e não o fazer perdurar (ARIÈS, 1986).

O ascetismo religioso cristão controlava qualquer desejo que ameaçasse o contrato conjugal, sustentando a prática sexual unicamente como procriação da espécie. Entre as proibições, estavam incluídas a masturbação e as relações sexuais entre pessoas do mesmo sexo, uma vez que estas eram controladas a todo instante pelo olhar do inquisidor. Esse olhar se constituía socialmente nos dispositivos de controles, registrando e averiguando

Vol. 01, N. 04, Out. - Dez., 2018 -www.revistas.unilab.edu.br/index.php/rebeh 
os desejos dos corpos, conforme acentua Michel Foucault: "O poder funciona como um mecanismo de apelação, atrai, extrai essas estranhezas pelas quais se desvela. O prazer se difunde através do poder cerceador e este fixa o prazer que acaba de desvendar" (FOUCAULT, 1988, p. 45).

A crença de que o homem era o "senhor do mundo" contribuiu para a construção sócio-histórica cultural para um sistema ocidental fortemente baseado no falocentrismo e, consecutivamente, no machismo, referenciando fortemente a ideologia patriarcal. Com a redefinição da perfeição anátomo-fisiológica no século XIX, homens e mulheres passaram a serem descritos pela metafísica dos seus corpos, forjando no imaginário social da época, a concepção da mulher como um "homem invertido". Esta concepção estava calcada na premissa de que a anatomia genital feminina era o inverso da anatomia masculina, pensamento este que ficou conhecido como o monismo sexual ou teoria do "modelo de sexo único" (one sex model). Toda a concepção médico-científica da época via na bissexualização dos ossos e nervos a ideia de que o corpo da mulher era o inverso do corpo do homem. Foi somente a partir da teoria do dualismo sexual ou doutrina do "modelo de dois sexos" (two sex model), que o pensamento científico passou a entender que a anatomia feminina era complementar à anatomia masculina, e não seu inverso, deixando o lugar de "homem invertido" vazio, mas não por muito tempo. Logo, os homossexuais passaram a ocupar esse lugar como "sujeitos invertidos", menos pela sua anatomia e mais pelo seu desejo sexual (LAQUEUR, 2001).

Foi a partir do século XIX, que as sexualidades consideradas periféricas começaram a ser criminalizadas, judicializadas e medicalizadas. Os estudos científicos sobre a sexualidade iniciam-se nesta época a partir da sexologia como conhecimento científico. Por exemplo, em 1832, o inglês Alexander Morrison publicou o tratado "Physionomy of Mental Disease", um dos primeiros textos a tratar cientificamente a homossexualidade. Neste texto, Morrison tentou documentar a realidade das fisionomias das doenças mentais, utilizando-se, para esse fim, de 109 pacientes com "características homossexuais". Três décadas mais tarde, em 1869, o jornalista, escritor e ativista dos direitos humanos austro-húngaro Karl-Maria Kertbeny criou o termo "homossexual" em substituição à palavra "pederastia”, transferindo do domínio jurídico para o domínio médico-científico esta manifestação da sexualidade (SIMÕES \& FACCHINI, 2009). Ou seja, o século XIX inaugurou novas formas de saber sobre a reprodução da espécie, da

Vol. 01, N. 04, Out. - Dez., 2018 - www.revistas.unilab.edu.br/index.php/rebeh 
família, dos indivíduos e suas relações do lidar com o outro: a governabilidade. Nas considerações de Foucault,

\begin{abstract}
A 'governabilidade' nasceu a partir de um modelo arcaico, o da pastoral cristã, apoiou-se em seguida em uma técnica diplomática-militar e finalmente como esta governabilidade só pôde adquirir suas dimensões atuais graças a uma série de instrumentos particulares de um novo modo de controle: a polícia (FOUCAULT, 1979, p. 293).
\end{abstract}

Sendo assim, a governabilidade do Estado se articula por meios de novos mecanismos de controle, mediante a polícia da higienização e da medicina psiquiátrica. Foram excluídos todas aqueles que não se enquadram à ideologia do modelo médicohigiênico uma vez que era preciso defender a sociedade: dos loucos, dos perversos, da criança masturbadora, da mulher histérica e dos homossexuais (FOUCAULT, 1988; 2002; 2003). Todos os indivíduos que de alguma forma não se enquadravam no padrão do homem burguês, branco e heterossexual eram considerados "anormais" ou marginais.

O indivíduo a ser corrigido vai aparecer nesse jogo, nesse conflito, nesse sistema de apoio que existe entre a família e, depois, a escola, a oficina, a rua, o bairro, a paróquia, igreja, a polícia, etc. Esse contexto, portanto, é que é o campo de aparecimento do indivíduo a ser corrigido (FOUCAULT, 2002, p. 72).

O sujeito da sexualidade foi um produto inventado por uma sociedade obcecada na produção de verdades localizados no corpo e na mente. Os discursos das scientias sexualis, construída na deiscência da vontade de saber do século XIX, foi a base de categorias estruturais na sociedade ocidental. As classificações heterossexual e homossexual foram categorizadas como sexualidades pelos dispositivos de poder, nomeando-as como normal ou patológico. Ambas as estruturas se tornaram potencializadas na sociedade, porém a heterossexualidade por estar calcada no sentido da reprodução da espécie contribuiu para a construção de um imaginário social de que esta seria a única possibilidade desejante saudável. Portanto a ocidentalidade reproduziu o modelo masculino como padrão cultural de potência para o avanço da raça humana, criando e sustentando o modelo de baluarte o homem, branco, cisgênero, heterossexual e burguês, nos padrões europeus, até o final do século XX.

Vol. 01, N. 04, Out. - Dez., 2018 -www.revistas.unilab.edu.br/index.php/rebeh 


\section{O sujeito de direito: a homossexualidade como categoria jurídico-política}

O que é cidadania homossexual? Ou melhor, o que faz do homossexual, antes considerado "sujeito da sexualidade", conquistar o reconhecimento jurídico-político em sua cidadania?

O conceito de "sujeito de direito" nasce a partir do reconhecimento da pessoa humana e está diretamente ligada à doutrina do jusnaturalismo. $\mathrm{O}$ jusnaturalismo ou

direito natural é uma teoria segundo a qual a igualdade e a desigualdade entre os homens estariam na sua natureza, e conforme afirma Costa (1998), três grandes desigualdades foram justificadas pela natureza: a primeira foi a desigualdade entre homens e mulheres, buscada na metafísica dos corpos; a segunda foi a desigualdade entre elite e povo, buscada principalmente na acumulação de bens e de capital, conforme a teoria marxista tratou de mostrar; por fim, entre os povos colonizadores e os povos colonizados, que tratou de garantir direitos aos que já estavam e os que vieram depois.

Foi somente com a Declaração Universal dos Direitos do Homem (MARSHALL, 1967) que houve uma síntese entre o passado e as aspirações do futuro em termos jurídicos à pessoa humana. Para tanto, o reconhecimento e a proteção dos direitos do homem precisou estar presente nas principais constituições democráticas modernas. Para Bobbio (2004), os direitos do homem e do cidadão se afirmaram historicamente em quatro gerações: a primeira, constituída pelos Direitos Individuais, que pressupõe uma igualdade formal perante a lei e consideram o sujeito de modo abstrato; a segunda, foi constituída pelos Direitos Coletivos, ou seja, direitos sociais nos quais o sujeito de direito é visto no contexto social ou analisado em uma situação concreta; a terceira, se refere aos Direitos dos Povos ou os Direitos de Solidariedade que defende os direitos transindividuais ou coletivos e difusos, tais como o direito do consumidor e àqueles relacionados à questão ecológica; por fim, os Direitos sexuais e reprodutivos de manipulação genética relacionados à biotecnologia e bioengenharia, ou seja, tratam de questões relacionadas sobre a vida e a morte e requerem a discussão da bioética (BOBBIO, 1996).

Para se alcançar uma sociedade democrática, são necessários três momentos ou movimentos históricos: os direitos do homem, a democracia e a paz, pois, sem o reconhecimento dos direitos do homem, não há democracia, e sem democracia, não existe as mínimas condições para pensar o sentido de paz. Em outras palavras: "a democracia é Vol. 01, N. 04, Out. - Dez., 2018 - www.revistas.unilab.edu.br/index.php/rebeh 
a sociedade dos cidadãos, e os súditos se tornam cidadãos quando lhes são reconhecidos em seus direitos; haverá paz estável, uma paz que não tenha a guerra como alternativa, somente quando existirem cidadãos não mais apenas deste ou daquele Estado, mas do mundo (BOBBIO, 2004, p. 7). Assim, para Bobbio, a democracia moderna constitui-se como a "sociedade dos cidadãos", noção que diz respeito à ampliação e ao alargamento dos direitos civis, políticos, sociais, culturais e ambientais ou dito e em outras palavras, é a "democracia do poder visível” ou "o governo do poder público" (BOBBIO, 1996).

O "sujeito de direito" é, portanto, todo aquele a quem a lei, no seu sentido mais amplo, atribui direitos e obrigações jurídicas e políticas na medida em que ele é regulado pelas leis do Estado e ou de um país. Dar à pessoa humana uma responsabilidade e um dever social é evidenciar o seu papel no seio da sociedade em que vive como aquele no qual não só é merecedor de direitos, mas também tem obrigações para o mesmo corpo social do qual participa, dito de outro modo, é evidenciar o contexto e as normas sociais nas quais ele vive, participa e intervém como um cidadão (SILVA, 2005).

O conceito de cidadania no plano das ciências humanas, sociais e jurídicas, é um tema vasto a ser detalhado. Em breves palavras, a cidadania expressa um conjunto de direitos dados à pessoa de participar da vida e do governo do seu povo. A cidadania não só instiga a pessoa a participar ativamente da vida jurídica e política do seu país, mas também induz que o governo dos povos legisle em favor dessas pessoas. Quem não tem cidadania, está à margem ou excluído da vida social e da tomada de decisões, consistindo em alguém inferior à outras pessoas (DALLARI, 1998). Estes direitos adquiridos, muitas vezes não são mantidos pela lei devido ao jogo de poder que se constitui por determinado grupo político. Isso favorece o cinismo de elites, que justificam a economia como foco principal de estabilidade governamental, desfavorecendo, por outro lado, o reconhecimento das categorias inferiores e vulneráveis da população. Segundo Trindade,

\footnotetext{
Fortalece-se por toda parte, o cinismo de elites tendentes a qualificar os trabalhadores - principalmente os excluídos do mercado e do consumo - mais ou menos como categoria inferior de humanos. Às vezes, isso manifesta-se de modo dissimulado. Outras vezes, extravasa como nostalgia de soluções fascistas contra os que são encarados como ameaça: migrantes, desempregados, grupos étnicos, LGBTs [grifo meu], etc. (TRINDADE, 1998, p. 58).
}

Portanto, é preciso que as pessoas sejam reconhecidas em sua igualdade e em suas diferenças, sejam elas de credo religioso, político, social, relações de gênero ou sexual. O

Vol. 01, N. 04, Out. - Dez., 2018 - www.revistas.unilab.edu.br/index.php/rebeh 
princípio de igualdade não é algo inato - nós não nascemos com ele -, pois ele é uma conquista da sociedade democrática. De acordo com Boaventura de Sousa Santos, "as pessoas e os grupos sociais têm o direito a ser iguais quando a diferença os inferioriza, e o direito a ser diferentes quando a igualdade os descaracteriza" (SANTOS, 1997, p. 30).

Para que indivíduos sejam incluídos nas políticas públicas de uma dada sociedade, é necessário que haja o reconhecimento do status de cidadania entre as pessoas. A demanda por reconhecimento é um fato recente na sociedade contemporânea e capitalista. Segundo Fraser (2007), na medida em que os movimentos sociais forçaram o reconhecimento das diferenças, das identidades cultuais e das desigualdades econômicas, numa sociedade globalizada e marcada por injustiças sociais, culturais e econômicos, buscou-se uma melhor redistribuição de bens e das riquezas sociais, ou seja, um reconhecimento valorativo e cultural das diferenças.

A luta pelo reconhecimento, no final do século XX, tornou-se um imperativo dos movimentos sociais que forçou a fomentação de políticas públicas por parte dos governantes em prol dos menos favorecidos, a partir da mobilização de importantes bandeiras em torno da nacionalidade, etnicidade, raça, gênero, identidade de gênero e sexualidade. A luta pelo reconhecimento de identidades de grupos e suas desigualdades, estabeleceu a necessidade de uma "política de reconhecimento" ou uma "política identitária" a fim de estabelecer os mesmos direitos entre aqueles que se sentem menos favorecidos, devido as suas particularidades. Foi o que aconteceu com os sujeitos homossexuais.

O reconhecimento e sentido de pertencimento social contribuíram para que os sujeitos homossexuais se unissem em prol da cidadania de uma identidade cultural específica de autoafirmação pela formação da política de identidade. Esta política se fez através do desejo e pela necessidade humana de estar inserido numa sociedade de direitos, no qual ter um "status" é fundamental. Segundo Nancy Fraser "status significa uma política que visa a superar a subordinação, fazendo do sujeito falsamente reconhecido um membro integral da sociedade, capaz de participar como outros membros como igual" (FRASER, 2007, p. 109).

Esse status de pertencimento começou a ser exigido a partir do momento em que os homossexuais não aguentavam mais as humilhações e os desprezos por parte da sociedade, sobretudo a partir do final dos anos 60, tal como aconteceu em Stonewall. Mas

Vol. 01, N. 04, Out. - Dez., 2018 - www.revistas.unilab.edu.br/index.php/rebeh 
antes mesmo que o evento de Stonewall entrasse para a história do movimento homossexual, em 1883 o psiquiatra alemão E. Kraepelin, fundador da psiquiatria moderna lançou seu Tratado de Psiquiatria, descrevendo os estados de fraqueza patológica fazendo referências à homossexualidade para várias outras categorias nosológicas. Em 1892, Richard Von krafft-Ebing publica o seu conhecido "Psycopathia Sexualis", que em suas inúmeras edições, chegou a adotar o termo homossexual cunhado por Kertbeny, classificando a homossexualidade entre as anomalias do instinto de reprodução da espécie, considerando-a uma degeneração quanto á procriação. Esses e outros movimentos da ciência médica provocou reações contrárias dos primeiros partidários do movimento antihomofóbico, conforme ocorreu em 1897, quando Magnus Hirshfeld, médico alemão e homossexual assumido, fundou com alguns colaboradores o Comitê Científico Humanitário (Wissenschaft-Humanitaires Komitee), objetivando defender os direitos dos homossexuais e revogar o Parágrafo 175 da lei alemã ${ }^{3}$ (PAOLIELL, 2013).

A revolta de Stonewall ${ }^{4}$, foi o estopim que proporcionou a revolta considerada a maios forte manifestação norte-americanas na luta por direitos a diversidade sexual e de gênero, abrindo a discussão e articulação organizada da construção do movimento de liberação gay na luta pelo reconhecimento, no qual edificou o grito Power gay como força de luta contra a opressão sexual. Esta revolta obteve muitas ramificações, encorajando e incentivando o reconhecimento de outras identidades em todo o mundo na luta por respeito e dignidade. Dos anos 70 em diante essas pessoas deram um basta, e passaram a reivindicar livre expressão por orientação sexual, constituindo uma "política de minoria". Desse modo, toda a luta pelo reconhecimento dos direitos civis dos homossexuais objetivou não só o reconhecimento público por parte do Estado de uma cidadania, mas também de seus status de "sujeitos de direitos" (SILVA, 2005).

As lutas políticas iniciaram a partir da reivindicação por direitos e reconhecimento da orientação sexual dos homossexuais. Mesmo com tantos obstáculos, os períodos históricos das lutas que se sucederam por direitos a existência e a liberdade, também se direcionou as lutas por direitos sociais, civis, sexuais e identitários. Contudo, essas lutas

\footnotetext{
${ }^{3}$ De acordo com Paoliello (2013), antes mesmo que a homossexualidade passasse a ser considerada uma doença, ela era considerada crime em alguns países da Europa, tal como ocorreu na Alemanha. Em 1871 a Alemanha criminalizou a homossexualidade por meio do parágrafo 175 do Código Criminal, vindo a ser eliminado em 1994.

${ }^{4}$ Rebelião ocorrida no bar Stonewall Inn em Nova Iorque numa manhã de 28 de junho de 1969, nos quais pessoas gays, lésbicas, travestis e transexuais foram abordados violentamente por policiais.
}

Vol. 01, N. 04, Out. - Dez., 2018 - www.revistas.unilab.edu.br/index.php/rebeh 
proporcionaram a criação de vários grupos políticos que passaram a lutar pela orientação sexual, identidades sexuais e de gênero como premissas ao direito da existência de uma população. Portanto, os(as) homossexuais lutam, não só por fazer parte do povo, mas pelo reconhecimento de sua cidadania.

\section{O sujeito homossexual e a trajetória sócio-histórica na luta por direitos: do Brasil colônia aos nossos dias}

Na história da sociedade brasileira há uma diversidade de expressões sexuais desde sua colonização até os dias atuais, que se constituem por diferentes atravessamentos culturais entre europeus, africanos e indígenas. No campo das relações sexuais, a homossexualidade no ocidente nunca foi bem recebida pois, as discriminações sempre fizeram parte da história por meio de violências forjadas pelo cristianismo. As origens dessas violências remontam períodos muito anteriores a colonização do Brasil, com os confessionários eclesiásticos europeus destinados a dar contornos sociais através dos discursos e comportamentos sexuais, forjado principalmente na ideia do "sujeito da sexualidade", comprovados por dados antropológicos, etnográficos, históricos e sociológicos que temos conhecimento. Senão, vejamos.

Nesse clima de misturas de etnias, costumes e crenças, o Rio de Janeiro foi o palco principal, por quase dois séculos, da verdadeira expressão "purgatório, da beleza e do $\operatorname{cas}^{5}$ ". Historicamente os antagonismos se fizeram pela flexibilidade, indecisão, equilíbrio e desarmonia entre as diferenças culturais que contribuíram para o favorecimento de efervescências plurais entre colonos e colonizados, dominadores e dominados, sagrado e profano, contornado por uma intensa (des)ordem à dominação patriarcal (FREYRE, 2006).

Entre o período colonial escravocrata e o início da Proclamação da República, muitas expressões da sexualidade foram documentadas pelo Santo Ofício, mostrando contradições entre o permitido e o proibido, entre o normal e o patológico, expressas nos corpos através das roupas que cobriam os colonos europeus, passando pelos corpos seminus dos negros escravizados africanos e, finalmente, da nudez da população indígena. Segundo o antropólogo Luís Mott (1988), mesmo com denúncias às instâncias

\footnotetext{
${ }^{5}$ Trecho da música "Rio $40^{\circ "}$ da cantora Fernanda Abreu.

Vol. 01, N. 04, Out. - Dez., 2018 - www.revistas.unilab.edu.br/index.php/rebeh
} 
inquisidoras coloniais, como o Santo Ofício, os negros resistiram à dominação ideológica, assumindo suas variações sexuais trazidas de suas culturas. Nesta época, cada etnia expressava suas diferenças no seu próprio corpo, cujas idiossincrasias se mostravam em permanente ebulição e contradições. Aos poucos, a subjetividade do povo local foi sendo constituída pela ideia de submissão das proibições corporais, influenciados pela cultura europeia imposta a ferro e fogo em meio ao ideal cristão da igreja.

Nessa terra de Santa Cruz, negros e índios, colonizados e colonizadores se deparavam com interdições de seus próprios desejos sexuais, que incluíam práticas sexuais adversas encaradas como abominável para além das relações reprodutivas. Por exemplo, a relação sexual entre pessoas do mesmo sexo para os índios Tupinambás ${ }^{6}$ era considerada comum, assim como era para algumas etnias africanas que aportaram no Brasil e cujo aspecto se situava em ritos de passagens e com aspectos do desejo sexual (COSTA, 2004; FREYRE, 2006).

Os homens efeminados tinham respeitabilidade entre os povos indígenas, pois recebiam um lugar próprio de importância entre os habitantes da tribo. Estes homens tinham sua função na tribo e eram dotados de poderes místicos, sejam eles curandeiros, pajés ou conselheiros. Eram assim conhecidos como couvades, termo usado pelos povos indígenas nas Américas para se referir aos homens bissexualizados que obtinham importância mística na tribo e cuja sexualidade poderia ser exercida indistintamente com homens e mulheres. Diferente daqueles conhecidos como bugres, que se diferenciavam na hierarquia tribal exercendo funções caseiras na mesma posição das mulheres indígenas (FREYRE, 2006). Esse comportamento comum entre os índios brasileiros se diferenciava dos colonizadores brancos e europeus, uma vez que designavam a prática sexual entre homens como homomixia ou sodomia, termos usados para classificar os homens efeminados e a prática sexual entre um tutor e seu aprendiz, muito semelhante ao que acontecia entre o Erastes e o Erômeno na antiguidade greco-romana. Os contrastes no comportamento sexual denotavam o quanto os indivíduos eram constituídos subjetivamente por sua cultura e subjugados pelo domínio colonizador. Por fim, havia também os ritos de passagens realizados pelos homens mais fortes da tribo. Estes homens guardavam a função de transmitir aos mais novos os ensinamentos da arte, da guerra, da

\footnotetext{
${ }^{6}$ Os Tupinambás eram uma das mais importantes tribos primitivas do Brasil (séculos XVI e XVII). Aos Tupinambás estavam filiados quase todos os povos aborígenes do litoral: os Tamoios, os Temiminós, os Tupiniquins, os Caetés, os Tabajaras, os Petiguaras, os Guajajaras (MÉTRAUX, 1979, p. XVIII).

Vol. 01, N. 04, Out. - Dez., 2018 - www.revistas.unilab.edu.br/index.php/rebeh
} 
caça e da incursão sexual, semelhante ao modelo greco-romano (FREYRE, 2006; FOUCAULT, 1988; 2003).

O comportamento homossexual podia ser encontrado também entre homens e mulheres da colônia que transitavam pela cidade à procura de negros escravos para sua satisfação sexual, mesmo com as interdições e controle da Igreja. Assim, a conduta proibicionista a tudo que fosse contrário a moral sexual "civilizada" e aos bons costumes era denunciada e registrada pelo Santo Ofício no período colonial brasileiro, demostrando que essas práticas se davam às escondidas entre "brancos e negros, com relações duradouras, contatos eventuais, estratagemas de sedução, violência do poderoso contra o mais fraco, ciúmes e paixões" (MOTT, 1988, p. 41).

$\mathrm{Na}$ era colonial brasileira, apesar de evidências cotidianas dos nativos que praticavam a homossexualidade, este mesmo comportamento era considerado como ato de sodomia, execrado e controlado para não existir. Mesmo não sendo considerada crime no Brasil, as relações homossexuais foram tendo desdobramentos culturais e sociais como anormal, desviante e periférico, pois, segundo afirma Jurandir Freire Costa "o homossexual era execrado, porque sua existência negava diretamente a função paterna, supostamente universal, constituída historicamente, a natureza do homem" (COSTA, 2004, p. 247).

Ao decorrer da história, os documentos escolásticos demostravam que haviam julgamentos contra homens que praticavam relações sexuais com outros homens na época inquisitorial e estes eram julgados e condenados à castração ou queimados nas fogueiras por crime de sodomia na Europa. Porém, nas terras de Santa Cruz, havia uma flexibilidade devido a existência das lutas simbólicas entre culturas diferentes que compunham tais condutas sexuais, possibilitando encontros, negociações e impasses. Se o "sujeito da sexualidade" na Europa oitocentista estava à serviço da ciência médico-psiquiatria, no Brasil colônia esse sujeito aparece nas interdições eclesiásticas cristã que viam no casal heteronormativo unicamente a possibilidade de intercurso sexual. A primeira e mais ínfima mudança se deu a partir da Proclamação da Independência, quando em 1830 D. Pedro I promulgou o Código Penal brasileiro com a retirada de qualquer referência à sodomia no Brasil (GREEN, 2000). A segunda mudança no que compete à compreensão 
do "sujeito sexual" na história do nosso país, só foi se dar a partir de um dos períodos mais críticos na história do Brasil: a ditadura militar ${ }^{7}$.

A ditadura militar durante o período entre 1964 e 1985, marca um dos tempos mais sombrios da nossa história, no qual todos aqueles que não se enquadravam no modelo da sociedade ideológica burguesa não serviam para a constituição de uma nação forte e saudável. O homossexual, nesta época, era o sujeito que mais se aproximava desta ameaça à tão esperada tradicional família brasileira cristã. Na década de 1970, aqueles que se identificavam como homossexuais se agruparam para formar a militância política contra todas as formas de marginalização à homossexualidade, inclusive dos partidos de esquerda, e o período da ditadura foi o início para esse impasse (SIMÕES \& FACCHINI, 2009, p. 13).

É importante considerar que na ditadura militar não havia um direcionamento específico de perseguição aos homossexuais, mas sim às resistências armadas de esquerdas que se organizavam contra o regime ou qualquer ameaça a moral e aos bons costumes, sendo alvo, primeiramente, aqueles que circulavam à noite procurando parceiros para diversão ou em busca de um profissional do sexo. Nessa configuração surge a figura dos "suspeitos", ou seja, aqueles que se enquadram nos estereótipos de perigosos e periféricos. Segundo Rafael F. Ocanha, “a subjetividade da aplicação da contravenção penal de vadiagem fazia com que estereótipos como os de gays, lésbicas e das travestis tornassem alvos preferenciais da polícia” (OCANHA, 2014, p. 151). Estes indivíduos eram considerados perigosos somente pela evidência de suas condutas sexuais "desviantes", contribuindo para prisões arbitrárias por acusação de vadiagem.

Esse marcador de diferença, inscrito pela sexualidade não-heterossexual, vai atravessar os homossexuais brasileiros através da história até o final da ditadura como sendo sujeitos dissidentes, colocados à margem da sociedade brasileira. Porém, vai ser essa marca identitária que também possibilitará questionamentos, por parte dos homossexuais, a existência de sujeitos. A marca que objetivou a identidade do homossexual se constituiu na sociedade como estigmas, impingindo sentimento de culpa, pecado, medo do ridículo, da prisão, do desemprego, do ostracismo por parte de amigos e familiares, possibilitando a formação dos guetos (MACRAE, 1983).

\footnotetext{
${ }^{7}$ Sabemos que durante a história do Brasil, o período correspondente à era Vargas também foi marcado por uma ditadura. Não nos cabe aqui, dar conta desse período em que as práticas sexuais desejantes não se constituíam ainda em movimentos sociais.
}

Vol. 01, N. 04, Out. - Dez., 2018 -www.revistas.unilab.edu.br/index.php/rebeh 
Vale lembrar que, durante o período da ditadura militar no Brasil, o processo de despatologização da homossexualidade estava em curso. Em 1973, por decisão unânime, a American Psychiatric Association (Associação Americana de Psiquiatria) e, em 1975, a American Psychological Association (Associação Americana de Psicologia), resolveram abolir a homossexualidade dos manuais classificatórios de transtornos mentais, ao compreendê-la como uma orientação sexual e uma variação do comportamento sexual (PAOLIELLO, 2013). Este foi o primeiro passo para a emergência de reconhecimento do homossexual como "sujeito de direito".

Devemos ressaltar ainda que o Conselho Federal de Psicologia, um ano antes da virada do século, colaborou definitivamente para a despatologização da homossexualidade. Em 1999, editou a Resolução N. 001/1999, estabelecendo normas de atuação para os psicólogos em relação à Orientação Sexual. Segundo esta resolução, as(os) psicólogas(os) devem atuar segundo princípios éticos profissionais, colaborando para a não discriminação de sujeitos homossexuais e promovendo o seu bem-estar, além de colaborar para uma reflexão crítica sobre o preconceito e o desaparecimento de discriminações contra comportamentos ou práticas homoeróticas. Além disso, as(os) psicólogas(os) devem exercer ações afirmativas favorecendo a despatologização de comportamentos ou práticas homossexuais, e estão impedidos de adotarem qualquer ação coercitiva para propor tratamentos não solicitados pelos seus pacientes, o que ficou conhecido como "cura gay" por parte da população em geral e da categoria profissional. Por fim, foi vedado aos psicólogos a participarem de qualquer pronunciamento público nos meios de comunicação de massa de modo a reforçar o preconceito e a discriminação contra os sujeitos homossexuais, sob pena de terem seus registros cassados pelo Conselho Federal de Psicologia ${ }^{8}$.

Enquanto nos Estados Unidos a guerra se travava no âmbito da ciência, entre o final dos anos de 1970 e o final da primeira década deste século, passamos a observar a mobilização de grupos de identidades homossexuais de gays e lésbicas no Brasil. A resistência estava voltada para a articulação política das identidades homossexuais, proporcionando cada vez mais espaços públicos voltados para a interação de gays e

\footnotetext{
${ }^{8}$ É importante ressaltar que o CFP cria uma resolução parecida com a resolução 001/99 contra a patologização das identidades de travestis e transexuais no Brasil em 2018 por meio da Resolução 001/18, estabelecendo normas de atuação para as psicólogas e os psicólogos contra o preconceito e discriminação das pessoas transexuais e travestis. https://bit.ly/2PVFUVW - acessado em 31 de julho de 2018.

Vol. 01, N. 04, Out. - Dez., 2018 -www.revistas.unilab.edu.br/index.php/rebeh
} 
lésbicas nas grandes cidades do Brasil, além da criação de informações, artes e literaturas sobre o assunto. Estes grupos colaboraram para a criação de materiais didáticos e informativos sobre o tema como encartes, jornais e revistas focando especificamente a homossexualidade à política, identidade, entretenimento, relacionamentos amorosos, fofocas e arte erótica.

O primeiro material a circular no Rio de Janeiro sobre homossexualidade e ativismo foi o encarte "O Snob”, e logo em seguida, o jornal de grande circulação entre o meio gay, o "Lampião da esquina”. O grupo ATOBÁ - Movimento de Emancipação Homossexual e o Grupo Triangulo Rosa, ambos do Rio de Janeiro, foram os primeiros grupos políticos articulados a discutirem sobre homossexualidade masculina e política no Rio de Janeiro, assim como o Grupo SOMOS em São Paulo que, junto ao Lampião da Esquina, criaram o primeiro Congresso Nacional Homossexual ocorrido na Associação Brasileira de Imprensa no Rio de Janeiro em 1979 (GREEN \& QUINALHA, 2014; SIMÕES \& FACCHINI, 2009).

Todos esses aparatos contribuíram para explicitação do caráter plural da sexualidade e para a construção das identidades das homossexualidades como "sujeitos de direito", facilitando para que comportamentos antes tidos como clandestinos, desviantes e subalternos agora pudessem estar mais visíveis e menos vulneráveis na sociedade brasileira. Estes atores sociais constituídos historicamente por um véu da criminalidade, da clandestinidade e da anormalidade, e que antes estavam sob o domínio de um saber-poder estabelecido pelos sistemas classificatórios médico-jurídico, agora passaram a se constituir como entidades políticas de luta existencial, para além das classificações masculinistas crivados na heteronormatividade 9 .

A pluralidade sexual foi surgindo aos poucos mostrando a cara nas reivindicações das ruas, exigindo direitos e políticas públicas específicas para a visibilidade e viabilidade pela constituição de uma comunidade de representação política. As reivindicações contra as discriminações de homossexuais, deram início a algo muito maior que foram as Paradas do Orgulho Gay no Brasil.

O período após a ditadura militar, com a redemocratização do estado de direitos, propiciou abertura para as discussões sobre as diferenças sexuais e de gênero no Brasil,

9 Ao invés de uma cultura heteronormativa, naquela época, seria melhor falarmos de um sistema heterossexual. Para o filósofo Paul Beatriz Preciado, o sistema heterossexual é um "dispositivo social de produção de feminilidade e masculinidade" (PRECIADO, 2014, p. 25).

Vol. 01, N. 04, Out. - Dez., 2018 - www.revistas.unilab.edu.br/index.php/rebeh 
facilitando a produção acadêmica para o debate interdisciplinar e retroalimentando o movimento homossexual. Dessas produções surgiram novos estudos e pesquisas sobre as diferenças sexuais e de gênero, possibilitando novas nomenclaturas identitárias para novas incursões de luta por direitos e reconhecimento da cidadania (CÂMARA, 2015, p. 374).

Soma-se a isso, a partir dos anos de 1980, uma doença que passou a preocupar a comunidade gay nos Estados Unidos e no mundo. A AIDS passou a ser conhecida e reconhecida como uma doença pertencentes apenas aos homossexuais no início da epidemia, fazendo com que governos de todo o mundo se mobilizassem para contê-la. A reinvindicação do movimento homossexual fez com que a indústria farmacológica encontrasse medidas eficazes no combate ao vírus do HIV. Como população mais vulnerável, os homossexuais passaram a ser alvo de inúmeras políticas públicas, por meio de campanhas publicitárias específicas e, posteriormente, para os grupos vulneráveis. A ideia de vulnerabilidade com relação à AIDS foi, mais uma vez, uma conquista do movimento homossexual envidando esforços para mais pesquisas, mais políticas públicas de proteção aos seus direitos, fazendo com que o Brasil fosse reconhecido em todo o mundo, até os anos 2000, como o país que mais tinha organizado medidas de contenção à epidemia nos mais diversos grupos vulneráveis (PARKER \& TERTO, 1998).

Na virada do século XX para o século XXI, os gays passaram a ser reconhecidos na sociedade brasileira como uma identidade sexual a partir da "politização da homossexualidade", termo utilizado para definir a junção de pessoas com os mesmos ideais na luta por cidadania. Era preciso debater as "questões gays" e seu impacto na sociedade no sentido de que a homossexualidade pudesse ser encarada para além dos questionamentos morais, que a história e o período da ditadura haviam deixado de legado para o século que se iniciava (ERIBON, 2008). Era preciso desconstruir os efeitos causados pelos mitos criados em relação as homossexualidades na sociedade. Foi neste sentido que o Brasil não privilegiou a homossexualidade no primeiro Plano Nacional de Direitos Humanos, corrigindo esse equívoco, a partir de 2001, na sua segunda versão, ao incluir quinze medidas de ações a serem adotadas pelo Governo Federal para o combate à discriminação por orientação sexual, criando o Conselho Nacional de Combate à Discriminação.

A partir de 2003, com a criação da Comissão Temática Permanente, iniciou-se pela primeira vez no Brasil um trabalho para receber denúncias de violação de direitos

Vol. 01, N. 04, Out. - Dez., 2018 - www.revistas.unilab.edu.br/index.php/rebeh 
humanos com base na orientação sexual. Na sequência, em 2004 no Governo do Presidente Luís Inácio Lula da Silva, deu início as primeiras ações sociais criando o programa Brasil Sem Homofobia, e logo após em 2008, as Conferências Nacional e Estaduais propondo amplitude de discussão para criação de políticas públicas em torno da população LGBT com objetivos de constituir reconhecimento de direito a igualdade a esses atores sociais, constituindo mudanças institucionais e sócio-histórica-culturais significantes para a sociedade brasileira (AGUIÃO, 2014).

O resultado dos debates oriundos das conferências forçou os governos estaduais, municipais e federal a proporem políticas públicas que atendessem às necessidades da população LGBT (FRANÇA, 2018). Um dos programas mais significativos contra as discriminações no Rio de Janeiro foi o programa estadual "Rio Sem Homofobia", oriundo do Programa Federal "Brasil Sem Homofobia”, constituído em 2008, que deu amplitude para outras ações governamentais, a saber: a) Criação de Centros de Referência de Combate à violência contra a população LGBT; b) Criação de atendimento telefônico 0800 para população LGBT; c) Tipificação de crime de homofobia nos boletins de ocorrência policiais; d) Autorização nos cartórios da cidade do Rio de Janeiro para realização de casamento civil entre pessoas do mesmo sexo; e) Divórcio civil para pessoas do mesmo sexo; f) Reconhecimento do nome social para travestis e transexuais em órgãos públicos; g) Leis municipais orgânicas contra preconceito e discriminação às pessoas LGBT em instituições comerciais; e, por fim, h) Intensificação e cobrança, por parte dos centros de referências, das mortes e violência por homofobia (RIO DE JANEIRO, 2011).

Como vimos, todas essas políticas públicas contribuíram substancialmente para a destituição do homossexual como "sujeito da sexualidade" e para que passássemos a vêlo como "sujeito de direito", uma vez que se buscou a garantia de sujeitos identificados pela sua orientação sexual, reconhecendo sua cidadania, seu direito à diferença e sua "liberdade para amar"

\section{Considerações Finais}

O surgimento do movimento homossexual no final do século XX, parâmetro de outros movimentos anteriores contra opressão às mulheres e os negros, foi um

\footnotetext{
${ }^{10}$ Título da música de Elza Soares no ano de 2007. Vol. 01, N. 04, Out. - Dez., 2018 -www.revistas.unilab.edu.br/index.php/rebeh
} 
acontecimento significante para a possibilidade crítica sobre a existência dos desejos contrários a heterossexualidade compulsória. Este movimento trouxe a instigação para que se observasse os desejos homossexuais para além das condutas jurídicas e científicas, antes julgadas como marginais e doentes. Deste movimento, a favor da pluralidade das identidades baseadas na diversidade sexual, puderam surgir novas reflexões e compreensões sobre a existência das diferenças sexuais e seus anseios desmistificando as hierarquias a priori.

A intensificação das lutas do movimento social homossexual deu sustento para a constituição e formação do reconhecimento da identidade gay no contexto sócio-históricocultural, ampliando a discussão sobre a existência de novas formas de desejos e a constituição de direito na formação de família. Por outro lado, o próprio significado de família constituída somente entre um homem e mulher, no século XIX, foi amplamente repensada, ampliando-se na cultura de direitos por meio das famílias formadas por casais de gays e lésbicas. Neste contexto as famílias homoafetivas passam a ser inseridas na cultura de direitos.

A partir do início do século XXI a discussão sobre democratização, globalização e direitos humanos no mundo ampliaram a discussão da cultura de direitos e a construção de políticas públicas para as classes minoritárias no Brasil. Surgem então as conferências LGBT estaduais, municipais e federal que deram fomentos ao debate das demandas sociais, culturais e jurídicas para o exercício da cidadania e visibilidade da comunidade LGBTI (AGUIÃO, 2014).

Por meio das conferências de políticas públicas a população LGBT conseguiram maior inserção social, nos quais proporcionaram novas formas de significações sociais e históricas para o reconhecimento das novas identidades no país. A questão homossexual trouxe ao século XXI uma potência, a quebra dos paradigmas normativos em relação a sexualidade hegemônica heteronormativa. Porém, os dispositivos disciplinares da anátomo-política dos corpos continuaram configurando novas políticas sexuais de controle (CARRARA, 2015).

Contudo, o surgimento das conferências regionais, estaduais e federal de políticas públicas para a população LGBT, a partir dos anos de 2008, vieram ratificando a importância dos direitos de formação e constituição das políticas públicas para a visibilidade desses atores e atrizes sociais, possibilitando a diminuição da invisibilidade.

Vol. 01, N. 04, Out. - Dez., 2018 -www.revistas.unilab.edu.br/index.php/rebeh 
Além, surgiram mais programas sociais voltados especificamente para esta população, sustentando o reconhecimento e amplitude dos direitos civis das identidades plurais. Por fim, após 2014 com a dialética entre as políticas de acesso à cidadania, a criação de políticas públicas e a polarizações políticas começaram a colidir, favorecendo novos debates e conflitos por uma nova luta: o reconhecimento das diferentes identidades que estariam em condições de dissidência na sociedade; mas isso é uma outra história.

\section{Referências}

AGUIÃO, Silvia. Fazer-se no "Estado": uma etnografia sobre o processo de constituição dos "LGBT" como sujeitos de direitos no Brasil contemporâneo. Tese de doutorado. Campinas: UEC, 2014.

ARENDT, Hannah. A condição humana. Rio de Janeiro: Forense Universitária, 2010.

ARIÈS, Philippe. O amor no casamento. In: ARIÈS, Philippe. \& BÉJIN, André. A Sexualidades ocidentais. $2^{a}$ ed. Rio de Janeiro: Editora Brasiliense, 1986.

BOBBIO, Norberto. A era dos direitos. $7^{\mathrm{a}}$ ed. Rio de Janeiro: Elsevier, 2004.

O futuro da democracia: uma defesa das regras do jogo. Rio de Janeiro: Paz e terra, 1986.

CÂMARA, Cristina. Um olhar sobre a história do ativismo LGBT no Rio de Janeiro. Revista do Arquivo Geral: Rio de Janeiro, n.9, p. 373-396, 2015.

CARRARA, Sergio. Moralidade, Racionalidades e Políticas sexuais no Brasil contemporâneo. MANA. N. 21, A. 2, p. 323-3455, 2015.

COSTA, Jurandir Freire. A face e o verso: estudos sobre o homoerotismo II. São Paulo: ed. Escuta, 1995.

Ordem médica e norma familiar. 5ª ed. Rio de Janeiro: ed. Graal, 2004.

A medicina como projeto social: controle do corpo. Cadernos CEPIA, Cap. 4 Saber Médico, corpo e sociedade, 1998, p. 127-138.

Vol. 01, N. 04, Out. - Dez., 2018 - www.revistas.unilab.edu.br/index.php/rebeh 
DALLARI, Dalmo. Direitos Humanos e Cidadania. São Paulo: Moderna, 1998.

ENGELS, Friedrich. A origem da família, da propriedade privada e do Estado. $4^{\mathrm{a}} \mathrm{ed}$. Rio de Janeiro: Civilização Brasileira, 1978.

ERIBON, Didier. Reflexões sobre a questão gay. Rio de Janeiro: Companhia de Freud, 2008.

FOUCAULT, Michael. A História da Sexualidade I: a vontade de saber. $13^{\mathrm{a}}$ ed. Rio de Janeiro: Graal, 1988.

. Os Anormais. São Paulo: Martins Fontes, 2002.

Microfísica do poder. $7^{\mathrm{a}}$ ed. Rio de Janeiro: Graal, 1979.

. História da Sexualidade II: o uso dos prazeres. 10a edição. Rio de Janeiro: Graal, 2003.

FRASER, Nancy. Reconhecimento sem ética?. Lua Nova, No70, 2007, 101-138.

FRANÇA, Alexandre Nabor Mathias. Movimentos sociais e o Programa Rio Sem Homofobia: uma trajetória de luta por políticas públicas e o reconhecimento da cidadania LGBT no Rio de Janeiro. Rio de Janeiro, 2018. Dissertação (Mestrado em Políticas Públicas em Direitos Humanos), Programa de Pós-Graduação de Políticas Públicas em Direitos Humanos, Universidade Federal do Rio de Janeiro, Rio de janeiro, 2018.

FREYRE, Roberto. Casa Grande \& Senzala: formação da família brasileira sob o regime da economia patriarcal. 51ª ed. Ver. São Paulo: ed. Global, 2006.

GREEN, James. \& QUINALHA, Renan. (orgs). Ditadura e homossexualidade: repressão, resistência e a busca da verdade. São Paulo: Edufscar, 2014.

GREEN, James. Além do Carnaval: a homossexualidade masculina no Brasil do século XX. São Paulo: Ed. UNESP, 2000.

Vol. 01, N. 04, Out. - Dez., 2018 - www.revistas.unilab.edu.br/index.php/rebeh 
LAQUEUR, Thomas. Inventando o sexo: Corpo e gênero dos gregos a Freud. Rio de Janeiro: Relume Dumará, 2001.

MACRAE, Edward. Em defesa do gueto. Novos Estudos, № 1, 1983.

MARSHALL, Thomas Humprey. Cidadania, Classe Social e Status. Rio de Janeiro: Zahar, p. 57-114, 1967.

MÉTRAUX, Alfred. A religião dos Tupinambás e suas relações com a das demais tribos Tupi-Guaranis. $2^{a}$ ed. São Paulo: ed. USP, 1979.

MOTT, Luiz. O sexo proibido: virgens, gays e escravos nas garras da inquisição. São Paulo: ed. Papirus, 1988.

OCANHA, Rafael Freitas. As rondas policiais de combate à homossexualidade na cidade de São Paulo (1976-1982). In: GRENN, James. \& QUINALHA, Renan. Ditadura e homossexualidades: repressão, resistência e a busca da verdade. São Carlos: EduFSCar, 2014, 149-175.

PARKER, Richard. \& TERTO, Veriano. Homossexualidade e aids no Brasil. Rio de Janeiro: ABIA, 1998.

PRECIADO, Paul Beatriz. Manifesto Contrassexual. São Paulo: N-1, 2014.

RIO DE JANEIRO. Relatório da II Conferência Estadual de Políticas Públicas e Direitos Humanos para LGBT/Por um Rio livre de pobreza e da discriminação: Promovendo a cidadania de lésbicas, gays, bissexuais, travestis e transexuais. Rio de Janeiro: Secretaria do Estado de Assistência Social e Direitos Humanos/Superintendência de Direitos Individuais, Coletivos e Difusos, 2011.

SILVA, Sergio Gomes. Sujeitos de direitos x sujeitos de deveres. Ciência e profissão: diálogos, 2, 2005, p. 56-57.

SIMÕES, Júlio Assis. \& FACCHINI, Regina. Na trilha do arco-íris: do movimento homossexual ao LGBT. São Paulo: Ed. Fundação Perseu Abramo, 2009.

Vol. 01, N. 04, Out. - Dez., 2018 - www.revistas.unilab.edu.br/index.php/rebeh 
SANTOS, Boaventura de Sousa. Por uma concepção multicultural de direitos humanos. Revista Crítica de Ciências Sociais, 48, 1997, p. 11 - 32.

TRINDADE, José Damião de Lima. Anotações sobre a história social dos direitos humanos. In: Procuradoria Geral do Estado de São Paulo. Direitos Humanos Construção da Liberdade e da Igualdade. São Paulo: Centro de Estudos da Procuradoria Geral do Estado, 1998, p. 23-163.

\title{
The political trajectory of the homosexual subject in the fight for rights
}

\begin{abstract}
This work aims to trace the historical period of struggle for the emancipation of homosexuality in Brazil by changing the status of "subject from sexuality" to "subject of rights". This will be achieved by redefining the medical-scientific structure of homosexuality until the beginning of some achievements in the area of rights and recognition of the citizenship of the homosexual subject, through Christian moral inquisition, criminalization and military ban until the founding of LGBT social movements.
\end{abstract}

Key-words: Homosexual Subject, Subject of Sexuality, Subject of Rights.

Recebido em: 09/09/2018

Aceito em: 23/11/2018

Vol. 01, N. 04, Out. - Dez., 2018 - www.revistas.unilab.edu.br/index.php/rebeh 